\title{
Inter- and intra-population variations in the response of the whelk Buccinum undatum to the predatory asteroid Leptasterias polaris
}

\author{
Rémy Rochette, Jeremy N. McNeil, John H. Himmelman* \\ Département de Biologie et GIROQ (Groupe Interuniversitaire de Recherches Océanographiques du Québec), \\ Université Laval, Ste-Foy, Québec, Canada G1K 7P4
}

\begin{abstract}
The escape responses of many animals are finely adjusted to the risks of predation encountered in nature. Adult whelks Buccinum undatum from a population sympatric with the predatory asteroid Leptasterias polaris more readily exhibited violent leaping escape maneuvers (foot contortions), produced larger quantities of mucus, and more efficiently escaped predator attacks than adult whelks from a population allopatric with the asteroid. However, newly emerged whelks (recruits) from both populations did not resort to strong escape maneuvers to flee $L$. polaris, but they nevertheless increased their crawling activity. The behavioral response of recruits appears to be predator-specific in the sympatric population, but not in the allopatric population. In the sympatric population, the tendency of whelks to exhibit foot contortions under predation risk increased with size. Our results suggest that where whelks coexist with $L$. polaris the capacity to recognize this predator as a threat is innate, and elaborate antipredator behaviors develop during ontogeny. We hypothesize that the greater responsiveness of large individuals is adaptive as it enables them to take advantage of the feeding opportunities that arise from close associations with L. polaris.
\end{abstract}

KEY WORDS: Gastropod - Buccinum undatum - Defensive responses · Predation risk - Sympatry Allopatry Ontogeny

\section{INTRODUCTION}

The adaptive value of morphological, physiological and behavioral antipredator traits has been examined from a number of perspectives. For instance, variations in the type and intensity of antipredator characteristics of prey animals have been related to the risk of predation encountered by different individuals within a population (reviewed by Sih 1987) and to that experienced by different populations within a species (many examples can be found in Huntingford \& Wright 1993, Mathis et al. 1993). Furthermore, many animals adjust their responses to the magnitude of danger that different encounters with predators represent, and make adaptive trade-offs between predation risk and other

- Addressee for correspondence.

E-mail: john.himmelman@bio.ulaval.ca essential activities, such as feeding and reproduction (Sih 1987, Lima \& Dill 1990)

Marine gastropods possess a variety of escape responses, including the discharge of defensive secretions, autotomy, color changes, and locomotory behaviors (Ansell 1969). These responses may be expressed by prey when touched by a predator, or upon detection of water-borne chemicals associated with predators. For example, gastropods respond to contact with asteroids, and to the saponins (steroid glycosides) these predators exude through their epidermis, particularly that of the tube feet (e.g. Feder 1963, Feder \& Lasker 1964, Mackie et al. 1968). Many of these escape responses appear to be efficient defense mechanisms (Feder 1963), and individuals exhibiting them have been shown to be less vulnerable to predators than 'non-responsive' conspecifics (McKillup 1982) or congeners (Kikuchi \& Doi 1987). 
In the shallow subtidal habitats of the western North Atlantic, a complex predator-prey relationship exists between the asteroid Leptasterias polaris and the common whelk Buccinum undatum (Himmelman \& Dutil 1991, Rochette et al. 1995). Upon detection of saponins from L. polaris, B. undatum becomes agitated, rocking its shell from side to side and increasing its rate of locomotion. If the threat is sufficiently strong, then somersault-type escape maneuvers, hereafter referred to as foot contortions, are exhibited (Harvey et al. 1987). In Europe, B. undatum exhibits the same response to the predatory asteroid Marthasterias glacialis (Feder 1967). Other species of gastropods possess similar escape maneuvers that are believed to deter asteroid predation (e.g. Ansell 1969, Feder 1972, Hoffman 1980, Kikuchi \& Doi 1987). If captured by $L$. polaris, whelks may use their radula to attack the asteroid's tube feet (R.R. pers. obs.), a behavior utilized by the slipper shell Crepidula fornicata to repel the oyster drill Urosalpinx cinerea (Pratt 1974). Although this behavior has not previously been reported for $B$. undatum, several workers have indicated that asteroid extracts induce contraction of the whelk's radula muscles (Fänge 1963, Feder \& Arvidsson 1967, Mackie et al. 1968).

Recent studies in the Mingan Islands (eastern Canada) have shown that Buccinum undatum is sensitive to the magnitude of the threat different encounters with predators represent. Firstly, whelks from this population differentiate among different asteroid species, adjusting the level of their responses to the risk of predation the asteroids represent (Legault \& Himmelman 1993). The strongest response is to Leptasterias polaris. Secondly, whelks can distinguish between foraging and inactive $L$. polaris ( $\mathrm{R}$. Rochette unpubl.), a discriminatory capacity also reported for other gastropods (Dayton et al. 1977. Phillips 1978). Finally, the response of whelks to predatory $L$ polaris varies depending on their feeding status and vulnerability (Rochette \& Himmelman in press). Interestingly, larger less vulnerable whelks occasionally aggregate in great numbers near feeding $L$. polaris to obtain food (Rochette et al. 1995).

In this study we compared the behavior of adult and newly recruited whelks from 2 localities, one where Leptasterias polaris is present and the other where $L$. polaris is absent, to determine if whelks living in sympatry with the predator exhibit stronger escape responses than whelks allopatric with the predator. Then, for whelks from the sympatric population, we examined the expression of foot contortions (the most violent behavioral response observed) by differently sized individuals, as a size-related responsiveness to $L$. polaris has been reported for whelks in the Mingan Islands (Harvey et al. 1987).

\section{MATERIALS AND METHODS}

Experimental animals and holding conditions. Sexuaily mature Buccinum undatum were collected by SCUBA divers at 2 localities in eastern Canada in May 1993; from Cap du Corbeau $\left(50^{\circ} 14^{\prime} \mathrm{N}, 63^{\circ} 35^{\prime} \mathrm{W}\right)$, off Ile du Havre in the northern Gulf of St. Lawrence where the predatory asteroid Leptasterias polaris is common, and from Bar Road (45 $05^{\prime} \mathrm{N}, 67^{\circ} 03^{\prime} \mathrm{W}$ ), in the Bay of Fundy where L. polaris is absent. Adult whelks varied from 80 to $100 \mathrm{~mm}$ in shell length at Cap du Corbeau, and from 40 to $60 \mathrm{~mm}$ at Bar Road. All whelks were transported to the Quebec Aquarium where they were held, for approximately $20 \mathrm{~d}$ prior to the bioassays, under a 12 h light: $12 \mathrm{~h}$ dark cycle in $16000 \mathrm{l}$ tanks containing recirculated water $\left(7^{\circ} \mathrm{C}, 30\right.$ to $32 \%$ salinity). Whelks from both populations appeared to adjust well to the holding conditions and readily fed upon the bivalve flesh (Mytilus edulis, Spisula polynyma, Mya truncata) which was provided to them every 3 to $4 \mathrm{~d}$. We evaluated their response to 20 to $25 \mathrm{~cm}$ diameter predatory asteroids $L$. polaris $(n=16)$, collected in April 1993 from Anse aux Basques, near Les Escoumins $\left(48^{\circ} 32^{\prime} \mathrm{N}, 69^{\circ} 41^{\prime} \mathrm{W}\right)$ in the St. Lawrence Estuary. Asteroids were held under the same conditions as whelks and regularly fed mussels ( $M$. edulis) until $5 \mathrm{~d}$ before the bioassays.

Buccinum undatum egg capsules, containing developing embryos, were collected in 1993 from Bar Road (May) and Cap du Corbeau (August) and kept until emergence in $2 \mathrm{~mm}$ mesh cages at the Quebec Aquarium under the same holding conditions as adults. Emergence occurred between 23 August and $20 \mathrm{Sep}-$ tember for Bar Road, and between 17 September and 1.4 October for Cap du Corbeau. The recruits (2 to $4 \mathrm{~mm}$ ) were provided bivalve (Mytilus edulis) flesh every 3 to $4 \mathrm{~d}$, but they did not start feeding until several days after emergence. Experiments were conducted from 7 to 11 October with recruits from Bar Road, and from 18 to 22 October with those from Cap du Corbeau. Recruits were tested with predatory asteroids Leptasterias polaris ( $\mathrm{n}=15$ ), non-predatory asteroids Henricia sp. $(\mathrm{n}=15)$, and fragments of a natural sponge Haliclona oculata $(n=4)$, all of which measured 35 to $45 \mathrm{~mm}$ in diameter and had been collected from Cap du Corbeau in August 1993

In June 1995, 30 asteroids (20 to $30 \mathrm{~cm}$ in diameter) and 30 whelks in each of 5 size classes (20 to 35,35 to 50,50 to 65,65 to 80 and 80 to $95 \mathrm{~mm}$ in shell length) were collected from Cap du Corbeau. All asteroids and whelks were brought to a wet laboratory at HavreSaint-Pierre and left undisturbed and without food in running sea water until tested 24 h later.

Adults from Cap du Corbeau and Bar Road. In the first series of experiments, whelks were gently touched 
on the underside of their foot, causing them to retract inside their shell, and then placed in individual 101 plastic containers $(25 \times 40 \times 10 \mathrm{~cm})$ As soon as the whelk's siphon became visible again, an asteroid was placed over the whelk. Observations were made for 5 min or until the whelk freed itself from the predator. The behavior of whelks was classified as: (1) remained inside the shell, (2) partial extension of the foot to resume an upright position but no locomotion, (3) full extension of the foot and crawling, or (4) violent foot contortions. We also quantified mucus production as: (1) nil, (2) weak (mucus trails could be felt on the bottom of the container), or (3) strong (abundant mucus covering or dripping from the whelk's foot). In each trial, an adult whelk from each site was exposed to the same asteroid. We used 16 different predators to test 16 whelks from both Cap du Corbeau (10 males, 6 females) and Bar Road (5 males, 11 females). In control tests for responses to non-predatory mechanical disturbances, whelks were covered with a piece of foam of similar size, shape and weight (under water) as the asteroids. Four such artificial asteroids were used to test 16 whelks from both Cap du Corbeau ( 9 males, 7 females) and Bar Road (5 males, 11 females).

In the second series of experiments, we examined responses to predator odors by placing whelks in 11 glass receptacles filled with water from an $8 \mathrm{l}$ container in which 1 asteroid had been held for 40 min. The protocol and behavioral categories were as in the contact experiment, except that observations were carried out for 2 min. A total of 15 adults from Cap du Corbeau ( 9 males, 6 females) and Bar Road ( 5 males, 10 females) were tested, each pair of whelks being exposed to the water-borne chemicals from a single asteroid. In the controls, 15 whelks from Cap du Corbeau (10 males, 5 females) and Bar Road ( 7 males, 8 females) were tested in untreated water from an 81 container.

Recruits from Cap du Corbeau and Bar Road. In each trial, a newly recruited whelk was first left undisturbed in a $50 \mathrm{ml}$ petri dish for $5 \mathrm{~min}$, and then an arm of a Leptasterias polaris was placed over it. The behavior of recruits was observed with the aid of a magnifying glass as the asteroid moved away, which usually took between 20 and $80 \mathrm{~s}$, and quantified using the same categories as for adults. We also estimated the locomotory rate of recruits for $60 \mathrm{~s}$ before and after treatment, using a $2 \times 2 \mathrm{~mm}$ grid on the bottom of the petri dish. In the control experiments, Henricia sp. remained in contact with the recruits for 20 to $100 \mathrm{~s}$, and the contact time with sponge fragments was matched to the previously tested L. polaris. For each treatment, 15 replicates were conducted each with a different asteroid and 5 recruits. Each recruit was only tested once.

Differently sized whelks from Cap du Corbeau. We first performed an escalated attack experiment. We began by placing a whelk in a $10 \mathrm{l}$ plastic container $(40 \times 25 \times 10 \mathrm{~cm})$ with still water and a 1 to $2 \mathrm{~cm}$ thick layer of sand on the bottom. When the whelk assumed an on-foot position, 1 arm of Leptasterias polaris was placed $1 \mathrm{~cm}$ in front of the whelk. Once the whelk started to crawl, its head region was touched 3 times with the extremity of the asteroid's arm, with the whelk being allowed to resume straight-line locomotion between contacts. The asteroid was then placed over the whelk until the prey exhibited foot contortions, or for a maximum of $60 \mathrm{~s}$. The responsiveness of each individual was scored from 0 to 3 depending on how rapidly it exhibited foot contortions: (0) never, (1) upon being mounted, (2) upon being touched, or (3) prior to any contact by the predator. One asteroid was used to test 1 whelk from each of the 5 size classes We planned on testing 15 whelks of each size class, but actual sample sizes varied between 10 and 15 as some individuals did not resume an on-foot position following transfer.

In the second experiment, we tested the response of different sized whelks to predator odors. Whelks were transferred into individual 4 l plastic receptacles $(25 \times$ $16 \times 10 \mathrm{~cm}$ ) containing water taken from a $9 \mathrm{l}$ container of sea water in which 1 asteroid had been held for $60 \mathrm{~min}$. Whelks were touched on the underside of the foot to ensure that they withdrew inside their shells, and then we recorded whether or not they exhibited foot contortions in the following 2 min. Fifteen asteroids were each used to test 1 whelk of each size class when held in $1,1.5,1.5,2$, and $2.5 \mathrm{l}$ of water, respectively. The volumes were adjusted so all whelks were completely submerged when being tested.

Statistical analysis. We used 2-tailed Fisher exact probability tests (Zar 1984) to compare the 2 populations with respect to the number of adult whelks that displayed: (1) foot contortions, (2) strong production of mucus, and (3) escape from Leptasterias polaris. Loglikelihood ratio analyses ( $G$-tests) of contingency tables (Zar 1984) were used to compare: (1) the tendency of recruits of a given population to crawl in response to different stimuli, and (2) the influence of population of origin on the tendency of recruits to crawl in response to a given stimuli. G-tests with adjusted critical levels (Dunn-Bonferonni method; Kirk 1982) were used for the multiple comparisons. To compare locomotory rates of recruits we first calculated, for each replicate, the average locomotory rate of individuals that crawled, and then compared average locomotory rates observed before and after treatment using non-parametric Mann-Whitney U-tests (Zar 1984). Pre- or posttreatment replicates in which no recruit crawled were not included in the analysis. Locomotory rates of recruits from a given population in response to different stimuli were compared using Kruskal-Wallis tests 
with correction for tied values, followed by non-parametric multiple comparisons where appropriate (Zar 1984). Finally, the relationship between the size of whelks and their tendency to exhibit foot contortions was quantified using an ordinal logistic regression in the escalated-attack experiment (the dependent variable was the score for responsiveness which varied between 0 and 3) and with a nominal logistic regression in the predator-odor experiment (the dependent variable was presence or absence of foot contortions) both regressions were executed with the JMP ${ }^{3}$ statistical package (SAS Institute Inc.).

\section{RESULTS}

\section{Adults from Cap du Corbeau and Bar Road}

The number of whelks Buccinum undatum exhibiting aversive behaviors to Leptasterias polaris, such as foot contortions and mucus secretion, was independent of sex (2-tailed Fisher exact probability tests, $p>0.4$ in all comparisons), so sexes were pooled for subsequent analyses. Geographic origin had a striking influence on the response of adult whelks to $L$. polaris. All whelks $(100 \%)$ from Cap du Corbeau (sympatric with L. polaris) exhibited foot contortions when mounted by

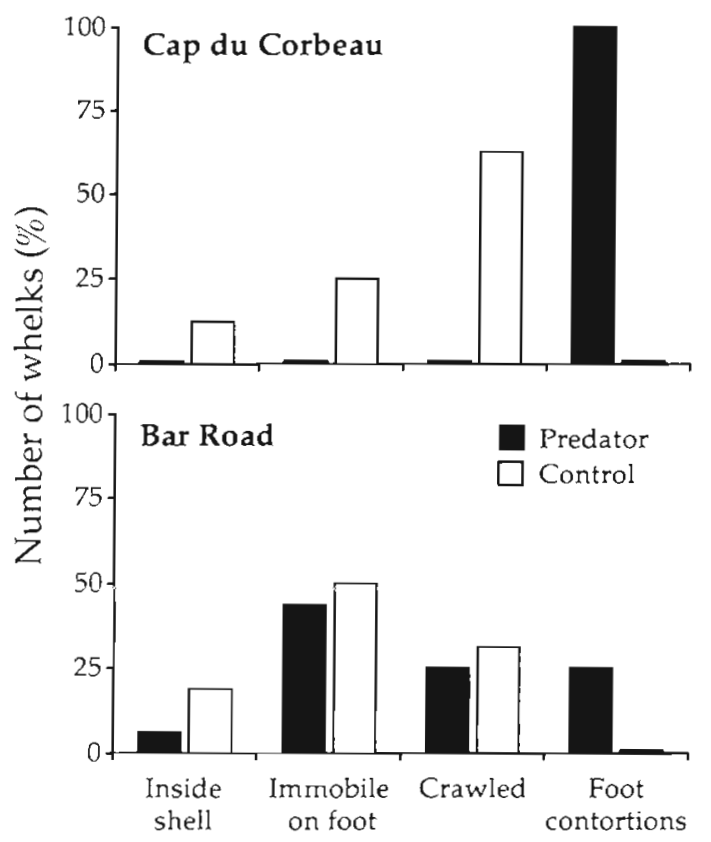

Behavior of whelks

Fig. 1 Buccinum undatum. Frequency distribution of the behavior of adult whelks sympatric (Cap du Corbeau, $\mathrm{n}=16$ ) and allopatric (Bar Road, $n=16$ ) with the predatory asteroid Leptasterias polaris, when mounted by a predator or a piece of toam of similar size and weight

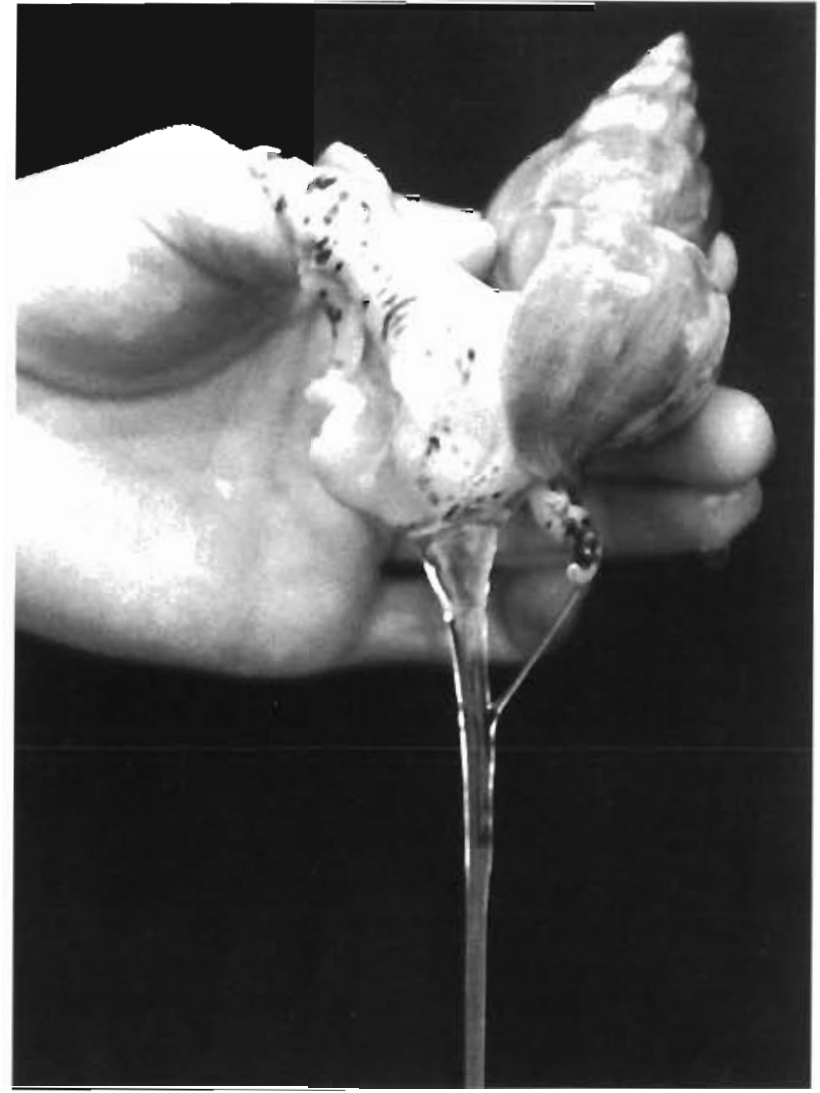

Fig. 2. Buccinum undatum. Production of large quantities of mucus by an adult whelk sympatric (Cap du Corbeau) with Leptasterias polaris after being mounted by a predator

L. polaris compared with only $25 \%$ for whelks from Bar Road (allopatric with L. polaris) (Fig. 1, p < 0.0001). Furthermore, the reaction time of whelks exhibiting foot contortions was 4-fold quicker (Mann-Whitney $U$ test, $U_{4,15}=56, p<0.05$ ) for whelks from Cap du Corbeau $(\bar{X}=20.0 \mathrm{~s}, \mathrm{SE}=3.6)$ than for whelks from Bar Road $(\bar{X}=82.8 \mathrm{~s}, \mathrm{SE}=39.8)$. A similar pattern was seen for the production of mucus, with $88 \%$ of the individuals from Cap du Corbeau producing large quantities (Fig. 2) compared with only 15\% for whelks from Bar Road (Fig. 3, p $<0.0001$ ). As a consequence of these differences in behavior patterns, $94 \%$ of the whelks from Cap du Corbeau escaped $L$. polaris during our experiment compared to only $19 \%$ for the whelks from Bar Road ( $p<0.0001)$. These population-related differences are specific responses to the predator, as in the control experiments neither foot contortions nor strong mucus production were observed in either population (Figs. 1 \& 3).

Whelks from Cap du Corbeau were also much more responsive to the odors of predators, as $73 \%$ of individuals exhibited violent foot contortions in response to water-borne predator chemicals compared with none 


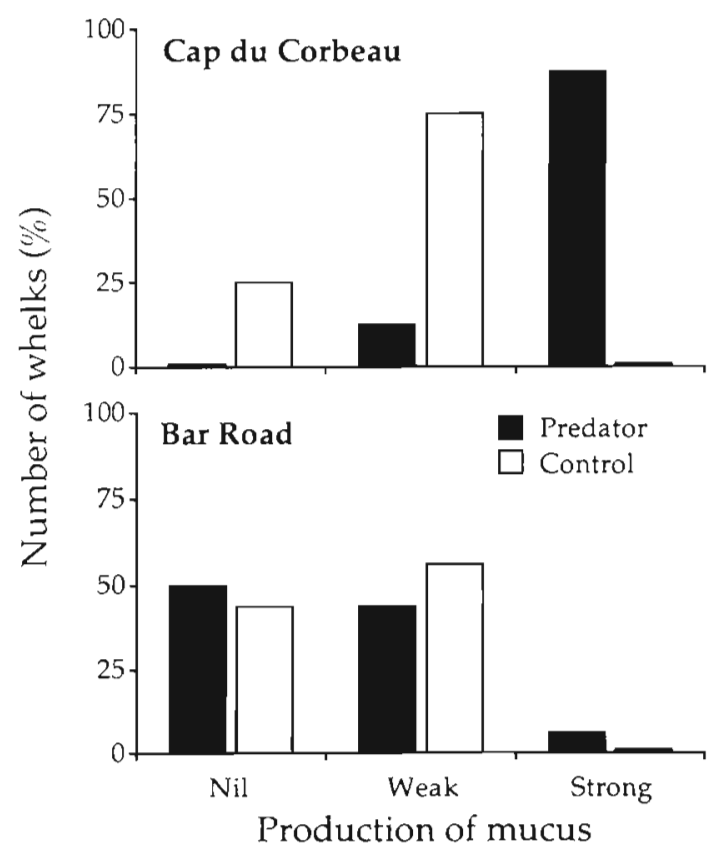

Fig. 3. Buccinum undatum. Frequency distribution of the mucus production response of adult whelks sympatric (Cap du Corbeau, $n=16$ ) and allopatric (Bar Road, $n=16$ ) with Leptasterias polaris, when mounted by a predator or with a piece of foam of similar size and weight

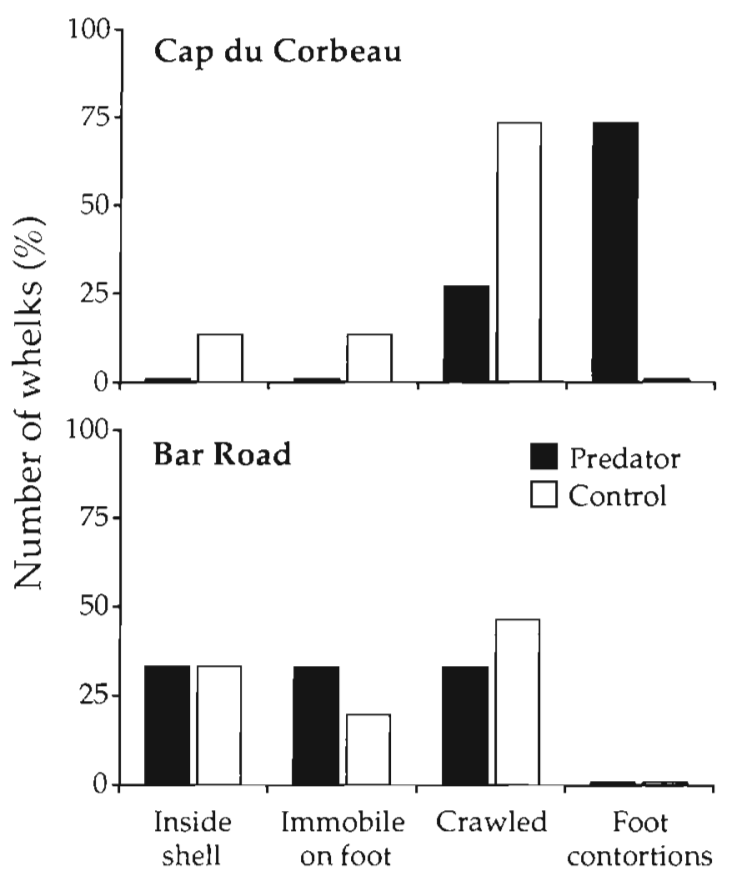

Behavior of whelks

Fig. 4. Buccinum undatum. Frequency distribution of the behavior of adult whelks sympatric (Cap du Corbeau, $\mathrm{n}=15$ ) and allopatric (Bar Road, $\mathrm{n}=15$ ) with Leptasterias polaris, when exposed to water-borne chemical cues from a predator or to untreated sea water for whelks from Bar Road (Fig. 4, p $<0.0001$ ). For whelks from Bar Road, L. polaris odors elicited no specific response, as no differences were detected between responses to predator-scented water and control sea water (Fig. 4).

\section{Recruits from Cap du Corbeau and Bar Road}

Newly recruited whelks from both populations virtually never exhibited violent foot contortions following contact by Leptasterias polaris, their most common response was crawling (Fig. 5). This cannot be explained by physical or energetic constraints, as recruits readily used foot contortions to right themselves. For Cap du Corbeau recruits, the proportion of whelks that crawled varied among treatments $(G=$ 36.58 , df $=2, p<0.0001$ ), being greater when contact was with $L$. polaris ( $G=34.94$, df $=1, p<0.0001$ ) or Henricia sp. $(G=15.56, \mathrm{df}=1, \mathrm{p}<0.0001)$ than with a sponge fragment. Higher response levels were observed with predatory ( $L$. polaris) than with nonpredatory (Henricia sp.) asteroids, although these dif-

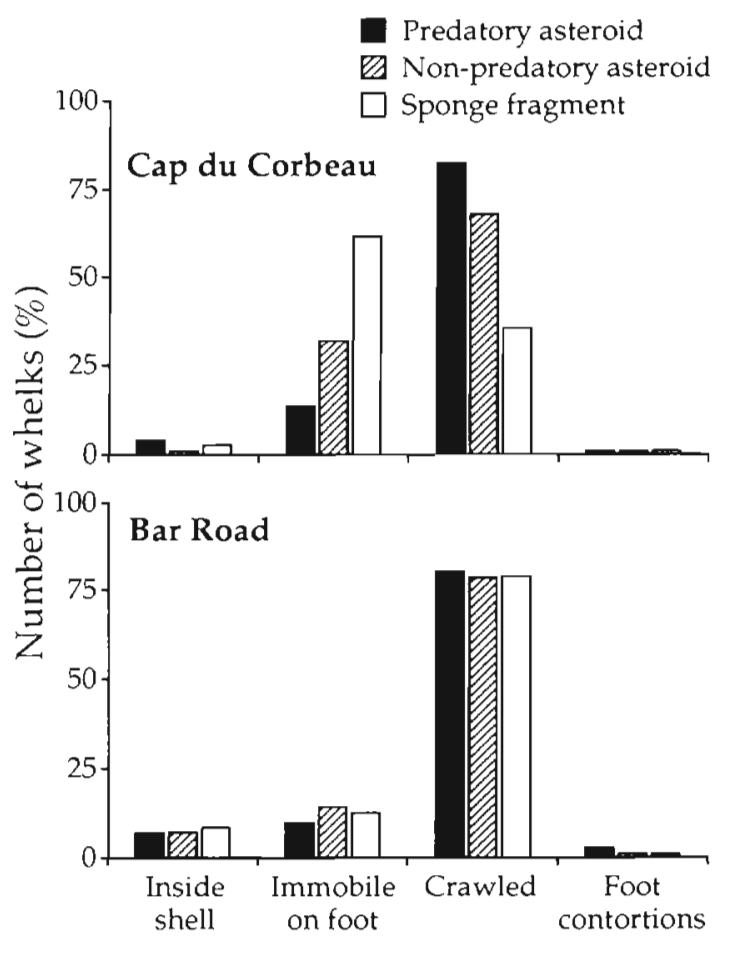

Behavior of whelks

Fig. 5. Buccinum undatum. Frequency distribution of the behavior of newly recruited whelks sympatric (Cap du Corbeau) and allopatric (Bar Road) with Leptasterias polaris, when contact is made with predatory asteroid $L$. polaris non-predatory asteroid Henricia sp., or a piece of sponge H. oculata 


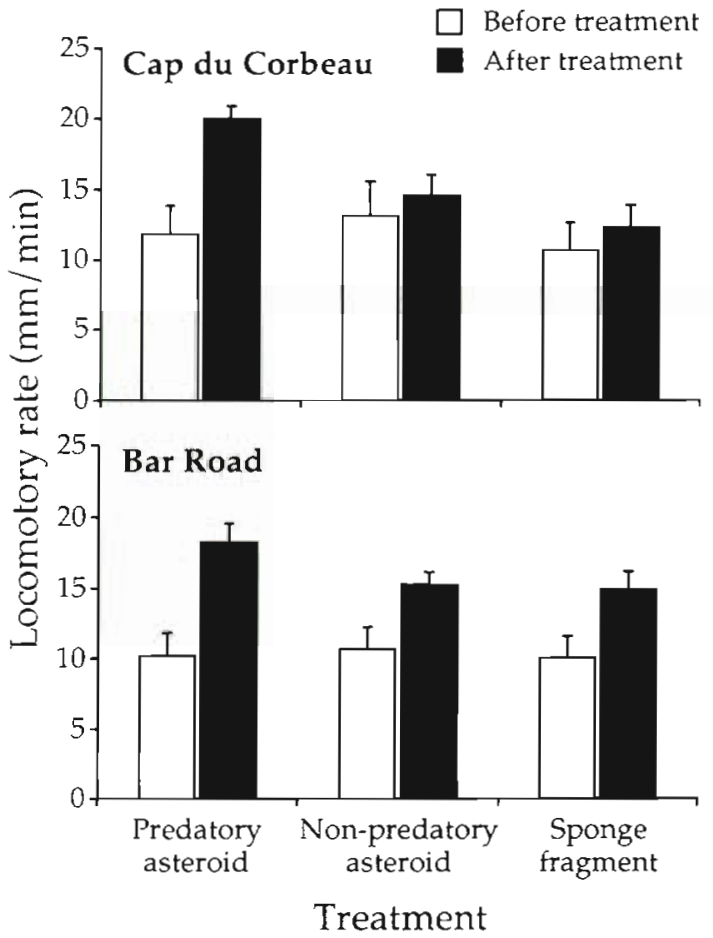

Fig. 6. Buccinum undatum. Locomotory rate of crawling newly recruited whelks sympatric (Cap du Corbeau) and allopatric (Bar Road) with Leptasterias polaris, before and after contact with predatory asteroid $L$. polaris, non-predatory asteroid Henricia sp., or a fragment of sponge $H$. oculata

ferences $(G=4.10, \mathrm{df}=1, \mathrm{p}=0.04$ ) were not below the critical level $(0.017)$ established for the multiple comparisons. In contrast, the proportion of Bar Road recruits that crawled was independent of the contact stimulus $(G=0.58$, df $=2, p=0.75)$, suggesting that any form of mechanical stimulation caused increased activity. Thus, whereas there was no difference in the response of both populations to $L$. polaris $(G=0.01$, $\mathrm{df}=1, p=0.92$ ), recruits from Cap du Corbeau were less likely to respond to non-specific mechanical disturbances $(G=23.41$, df $=1, \mathrm{p}<0.0001)$ than their counterparts from Bar Road. It should be noted that the number of recruits crawling prior to stimulation was higher $(G=31.78$, df $=1, \mathrm{p}<0.001)$ for the Bar Road $(38.9 \%)$ than for the Cap du Corbeau (15.1\%) population.

A similar inter-population difference was seen in the rate of locomotion following contact. Recruits from Cap du Corbeau only increased speed following contact with Leptasterias polaris (Fig. 6, Table 1). Consequently, post-treatment speeds differed significantly among treatments $(H C=13.7, \mathrm{df}=2, \mathrm{p}<0.005)$, being greater following contact with $L$. polaris than following contact with Henricia sp. or a sponge (in both cases p<
Table 1. Buccinum undatum. Results of Mann-Whitney $U$-tests estimating changes in locomotory rates of $B$. undatum recrults from 2 populations, one sympatric and the other allopatric with the predatory asteroid Leptasterias polaris, following contact with dufferent stimuli. Only replicates $(n)$ in which at least $1 \mathrm{re-}$ cruit crawled were included in these analyses

\begin{tabular}{|c|c|c|c|c|}
\hline Treatment & $n$ before & n after & $U$ & $\mathrm{p}$ \\
\hline \multicolumn{5}{|c|}{ Cap du Corbeau (sympatric) } \\
\hline Fragments of sponge & 8 & 13 & 61 & $>0.4$ \\
\hline Henricia sp. & 7 & 15 & 59 & $>0.4$ \\
\hline Leptasterias polaris & 11 & 15 & 149 & $<0.001$ \\
\hline \multicolumn{5}{|l|}{ Bar Road (allopatric) } \\
\hline Fragments of sponge & 14 & 15 & 161 & $<0.02$ \\
\hline Henricia sp. & 15 & 15 & 189 & $<0.002$ \\
\hline Leptasterias polaris & 14 & 15 & 177 & $<0.002$ \\
\hline
\end{tabular}

0.05). In contrast, recruits from Bar Road significantly increased their locomotory rate in all 3 treatments (Fig. 6, Table 1), and post-treatment speeds were similar $\left(H_{C}=4.1, \mathrm{df}=2, p=0.10\right)$. These results again support the idea that recruits from Bar Road show a maximum level of response to any mechanical stimulus, whereas those from Cap du Corbeau exhibit some degree of discrimination.

\section{Differently sized whelks from Cap du Corbeau}

There was a positive relationship between the size of whelks and their tendency to exhibit foot contortions in both the escalated attack experiment (Fig. 7, log-likelihood $\chi^{2}=4.43, \mathrm{df}=1, \mathrm{p}=0.035$ ), and in the experiment with water-borne chemicals from $L$. polaris (Fig. 8 ; loglikelihood $\chi^{2}=15.95, \mathrm{df}=1, \mathrm{p}<0.0001$ ). While scores for responsiveness varied considerably between similar sized individuals in the simulated escalated attack (Fig. 7), only $<40 \mathrm{~mm}$ whelks did not exhibit foot con-

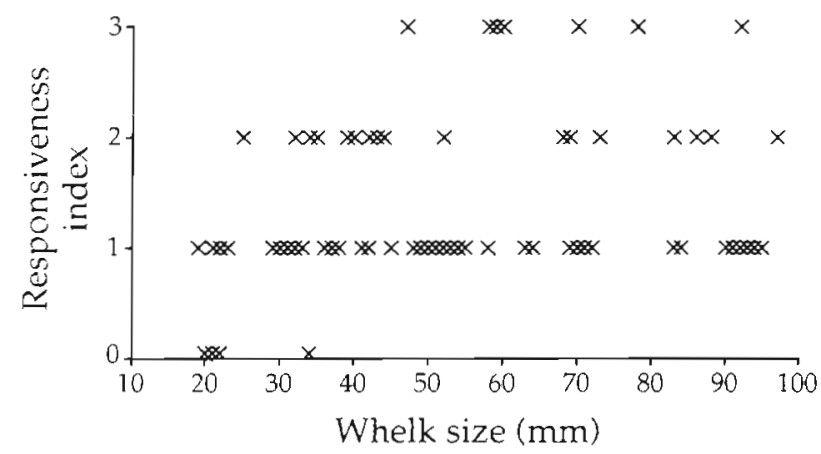

Fig. 7. Buccinum undatum. Relation between the size of whelks at Cap du Corbeau and their responsiveness to Leptastenas polaris, based on the score of individual whelks in a simulated escalated attack 


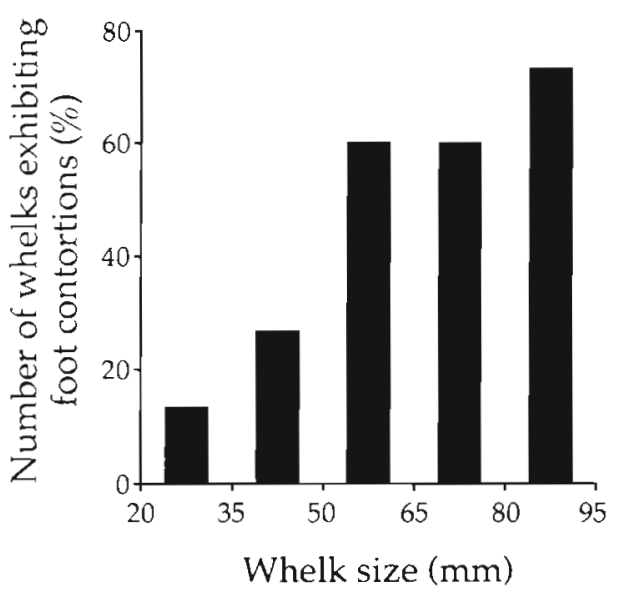

Fig. 8. Buccinum undatum. Relation between the size of whelks at Cap du Corbeau and their responsiveness to Leptasterias polaris, based on the proportion of differently sized whelks ( $\mathrm{n}=15$ per size class) exhibiting foot contortions in response to water-borne chemicals from $L$. polaris

tortions at any stage of the attack (score of 0 ), while only individuals $>45 \mathrm{~mm}$ exhibited foot contortions before being touched by the predator (score of 3 ).

\section{DISCUSSION}

The population of Buccinum undatum from Cap du Corbeau, which is sympatric with Leptasterias polaris, exhibits stronger and more precise antipredator responses than the population at Bar Road, which is allopatric with the asteroid. The low responsiveness of whelks in the Bay of Fundy may be related to a general low risk of predation by asteroids. Thomas \& Himmelman (1988) found that adult whelks from 2 other localities in the Bay of Fundy only exhibit weak responses to the asteroids Asterias vulgaris and Crossaster papposus. McKillup (1982) describes a similar situation with 2 populations of the gastropod Littorina unifasciata. In South Australia, L. unifasciata coexists with the predatory whelk Lepsiella vinosa and it rapidly climbs out of tidal pools into which $L$. vinosa is experimentally introduced. In contrast, when $L$. vinosa are transported from Australia and introduced into tidal pools in New Zealand, $L$. unifasciata exhibits only weak responses and consequently, many individuals are killed and consumed. Variations in escape behaviors of adult $B$. undatum, such as those we document between populations in the northern Gulf of St. Lawrence and Bay of Fundy, may occur over much shorter distances since the whelk's mode of reproduction, involving internal fertilization and benthic embryonic development, strongly limits gene flow between adjacent populations, thereby favoring adaptation to local conditions (e.g. Beherens Yamada 1989).
Adult whelks at Cap du Corbeau exhibit vigorous defensive movements, mucus secretion and flight when exposed to water-borne chemicals from Leptasterias polaris and when contact is made with this predator. The importance of these behaviors in reducing the risk of predation is suggested by the fact that $94 \%$ of the whelks from Cap du Corbeau escaped $L$. polaris during our experiments, compared to only $19 \%$ for whelks from Bar Road. Shell rocking and foot contortions reduce the ability of $L$. polaris to use its podia and arms to constrain its prey (see also Feder 1972 , Hoffman \& Weldon 1978). The mucus whelks secrete could serve a similar function, as well as potentially being distasteful and repellent to asteroids (Ansell 1969). In addition, once the whelk is free, contortions of the foot induce leaping movements that rapidly distance it from the asteroid.

In contrast to the adults, recruits from Cap du Corbeau never exhibited foot contortions; their sole response when touched by Leptasterias polaris was to display an increase in crawling activity (increases in tendency to crawl and locomotory rate). Nevertheless, they crawled more frequently following contact with L. polaris than following control treatments, and their rate of locomotion increased significantly when contact was made with L. polaris, but not following contact with non-threatening stimuli. These results suggest that whelks from Cap du Corbeau are born with the capacity to discriminate different stimuli, and that they exhibit maximum responses to important predators. Recruits from Bar Road, on the other hand, show an increase in locomotory rate irrespective of the type of stimulus employed. Similarly, mosquito larvae Culex pipiens sympatric with the predatory bug Notonecta undulata display precise responses to this predator; whereas the larvae of Aedes aegypti, which shares no evolutionary history with $N$. undulata, respond similarly to the predator and to control disturbances (Sih 1986). Sih (1986) suggests these 2 species differ in the way they estimate predation risk; the behavior of $C$. pipiens being mediated by chemical cues indicating predation risk, and that of $A$. aegypti being a response to disturbance per se. The same argument can be made to account for the differences observed with newly recruited whelks from Cap du Corbeau and Bar Road. However, it is with some reserve that we conclude that recruits from Bar Road did not discriminate L. polaris from control disturbances, since the probability value for the comparison of locomotory rates among treatments was low $(p=0.10)$. This question warrants further investigation.

Although newly recruited and adult whelks from Cap du Corbeau exhibit specific responses to Leptasterias polaris, the expression of foot contortions, the whelks' most violent escape response, increases with 
the size of the whelk. Size-related changes in antipredator responses have previously been reported in 2 species of gastropods (Hoffman \& Weldon 1978 , Doering \& Phillips 1983). In both species, the ontogenic shifts in responsiveness appear related to the prey's probability of encountering predators. At Cap du Corbeau, low activity levels, cryptic behaviors (Himmelman \& Hamel 1993) and active avoidance of $L$. polaris by whelks of all sizes (Rochette et al. 1995) probably reduce their overall encounter rate with predators. However, larger whelks inhabit the sediment zone where large asteroids forage on endobenthic bivalves (Rochette \& Himmelman in press), and at times they aggregate in great numbers near feeding $L$. polaris to obtain food, either by feeding on left-overs, stealing some of the asteroid's prey while it is feeding, or capturing infaunal organisms exposed by the asteroid's digging activities (Rochette et al. 1995). We hypothesize that the ultimate cause (Alcock 1984: p. 4) of the ontogenic shift in whelks' responsiveness is that it enables larger individuals to associate intimately with L. polaris for feeding benefits.

However, even small individuals would likely benefit from a strong and complete defensive response as it should increase their chances of surviving encounters with predators. Predation experiments in which differently sized Leptasterias polaris were offered differently sized whelks indicated that prey vulnerability and size are inversely related at Cap du Corbeau (Rochette \& Himmelman in press). Furthermore, in the field, we have observed $L$. polaris feeding on whelks as small as 10 to $15 \mathrm{~mm}$. Although we do not know whether recruits (2 to $4 \mathrm{~mm}$ ) are under risk of predation in nature, they are avidly ingested by L. polaris in the laboratory. The weak tendency of small whelks to exhibit foot contortions to escape $L$. polaris might be related to the ratio of costs (energetics of flight; Denny 1980, Kideys \& Hartnoll 1991) to benefits (potential of escape and nutritional gains) of violent flight responses. Another hypothesis is that the ontogenic development of the response of whelks to L. polaris requires experience with predators. Animals as 'simple' as ciliate protozoans adaptively modify their behaviors following experience with predators (Kusch 1993). Since the escape responses of gastropods are under the control of a simple neural network (e.g. Willows \& Hoyle 1969), learning might simply take the form of sensitization, the response increasing with increasing exposure to stimuli. Alternatively, whelks may be capable of associative averse conditioning, as Walters et al. (1979) report for the nudibranch Aplysia californica. In $A$ californica, learning even leads to an internal state that is functionally equivalent to fear in higher mammals (Walters et al. 1981). Studies on sticklebacks, minnows and guppies suggest that inheritance and ex- perience both play a role in the development of antipredator responses of freshwater fishes (Huntingford \& Wright 1993). We are currently investigating how escape responses develop in Buccinum undatum.

Acknowledgements. We are extremely grateful to the Québec Aquarium for the reliable laboratory conditions they provided, to M.-J. Maltais and J. Maltais for therr assistance in the laboratory, and to S. Morissette for helping in collecting the organisms used in this study. This project was financially supported by NSERC and FCAR grants to J.H.H. A FCAR scholarship to R.R. is gratefully acknowledged.

\section{LITERATURE CITED}

Alcock J (1984) Animal behavior an evolutionary approach, 3rd edn. Sinauer Associates Inc, Sunderland, MA.

Ansell AD (1969) Defensive adaptations to predation in the Mollusca. Proc Mar Biol Ass India Symp Ser 3:487-512

Beherens Yamada S (1989) Are direct developers more locally adapted than planktonic developers? Mar Biol 103: $403-411$

Dayton PK, Rosenthal RJ, Mahen LC, Antezana T (1977) Population structure and foraging biology of the predaceous Chilean asteroid Meyenaster gelatinosus and the escape biology of its prey. Mar Biol 39:361-370

Denny $M$ (1980) Locomotion: the cost of gastropod crawling Science 208:1288-1290

Doering $\mathrm{PH}_{t}$ Phillips DW (1983) Maintenance of the shorelevel size gradient in the marine snail Tegula funebralis (A. Adams): importance of behavioral responses to light and sea star predators. J Exp Mar Biol Ecol 67:159-173

Fänge R (1963) Toxic factors in starfishes. Sarsia 10:19-21

Feder HM (1963) Gastropod defensive responses and their effectiveness in reducing predation by starfishes. Ecology $44: 505-512$

Feder HM (1967) Organisms responsive to predatory sea stars. Sarsia 29:371-394

Feder HM (1972) Escape responses in marine invertebrates. Sci Am 227:92-100

Feder HM, Arvidsson J (1967) Studies on a sea-star (Marthasterias glacialis) extract responsible for avoidance reactions in a gastropod (Buccinum undatum). Ark Zool 19:369-379

Feder HM, Lasker R (1964) Partial purification of a substance from starfish tube feet which elicits escape responses in gastropod molluscs. Life Sci 3:1047-1051

Harvey C, Garneau FX, Himmelman JH (1987) Chemodetection of the predatory seastar Leptasterias polaris by the whelk Buccinum undatum. Mar Ecol Prog Ser 40:79-86

Himmelman JH, Dutil C (1991) Distribution, population structure, and feeding of subtidal seastars in the northern Gulf of St. Lawrence. Mar Ecol Prog Ser 76:61-72

Himmelman JH, Hamel JR (1993) Diet, behaviour and reproduction of the whelk Buccinum undatum in the northern Gulf of St. Lawrence, eastern Canada. Mar Bıl 116:423-430

Hoffman DL (1980) Defensive responses of marne gastropods (Prosobranchı, Trochidae) to certain predatory seastars and the dire whelk, Searlesia dira (Reeve). Pac Sci 34 : $233-243$

Hoffman DL, Weldon PJ (1978) Flight responses of two intertidal gastropods (Prosobranchia: Trochidae) to sympatric predatory gastropods from Barbados. Veliger 20:361-366

Huntingford FA, Wright PJ (1993) The development of adaptive variation in predator avoidance in freshwater fishes. Mar Behav Physiol 23:45-61 
Kideys AE, Hartnoll RG (1991) Energetics of mucus production in the common whelk Buccinum undatum L. J Exp Mar Biol Ecol 150:91-105

Kikuchi T, Dol T (1987) Defensive escape response of two trochid sand snail species of the genus Umbonum: the effect of species-specific escape response to asteroid predators. Publ Amakusa Mar Biol Lab 9:47-65

Kirk RE (1982) Experimental design: procedures for the behavioral sciences. Brooks/Cole Publishing Company Monterey

Kusch J (1993) Behavioural and morphological changes in ciliates induced by the predator Amoeba proteus. Oecologia 96:354-359

Legault C, Himmelman JH (1993) Relation between escape behaviour of benthic marine invertebrates and the risk of predation. J Exp Mar Biol Ecol 170:55-74

Lima SL, Dill LM (1990) Behavioral decisions made under the risk of predation: a review and prospectus. Can J Zool 68 619-640

Mackie AM, Lasker R, Grant PT (1968) Avoidance reactions of a mollusc Buccinum undatum to saponin-like surfaceactive substances in extracts of the starfish Asterias rubens and Marthasterias glacialis. Comp Biochem Physiol 26 $415-428$

Mathis A, Chivers DP, Smith RJF (1993) Population differences in responses of fathead minnows (Pimephales promelas) to visual and chemical stimuli from predators. Ethology 93:31-40

McKillup SC (1982) The selective advantage of avoidance of the predatory whelk Lepsiella vinosa (Lamark) by Littorina unifasciata (Philippi). J Exp Mar Biol Ecol 63:59-66

This article was submitted to the editor
Phillips DW (1978) Chemical mediation of invertebrate defensive behaviors and the abllity to distinguish between foraging and inactive predators. Mar Biol 49:237-243

Pratt DM (1974) Behavioral defenses of Crepidula fornicata against attack by Urosalpinx cinerea. Mar Biol 27:47-49

Rochette R, Himmelman JH (in press) Does vulnerability influence trade-offs made by whelks between predation risk and feeding opportunities? Anim Behav

Rochette R, Morissette S, Himmelman JH (1995) A flexible response to a major predator provides the whelk Buccinum undatum L. with nutritional gains. J Exp Mar Biol Ecol 185:167-180

Sih A (1986) Antipredator responses and the perception of danger by mosquito larvae. Ecology 67:434-441

Sih A. (1987) Predators and prey lifestyles: an evolutionary and ecological overview. In: Kerfoot WC, Sih A (eds) Predation: direct and indirect impacts on aquatic communities. University Press of New England, London, p 203-224

Thomas MLH, Himmelman JH (1988) Influence of predation on shell morphology of Buccinum undatum L. on Atlantic coast of Canada. J Exp Mar Biol Ecol 115:221-236

Walters ET, Carew TJ, Kandel ER (1979) Classical conditioning in Aplysia californica. Proc Natl Acad Sci USA 76 $6675-6679$

Walters ET, Carew TJ, Kandel ER (1981) Associative learning in Aplysia: evidence for conditioned fear in an invertebrate. Science 211:504-506

Willows AOD, Hoyle G (1969) Neuronal network triggering a fixed action pattern. Science 166:1549-1551

Zar JH (1984) Biostatistical analysis, 2nd edn. Prentice-Hall, Englewood Cliffs, NJ

Manuscript first received: April 24, 1996

Revised version accepted: June 25, 1996 